Peter Kranke

Norbert Roewer

Ralf M. Muellenbach

\section{"Colloid twice daily" is not fluid resuscitation! Inappropriate inclusion of clinical trials in meta-analyses may distract from gaps in evidence}

Accepted: 3 May 2013

Published online: 5 June 2013

(C) Springer-Verlag Berlin Heidelberg and ESICM 2013

A reply to this letter can be found at: doi:10.1007/s00134-013-2962-4.

\section{Dear Editor,}

We read with interest the recent systematic review investigating the impact of hydroxyethyl starch administration as part of initial fluid resuscitation for severe sepsis on mortality [1]. The authors claimed to have identified "prospective randomised controlled trials (RCTs) in adult patients with severe sepsis receiving $6 \%$ tetrastarch (of potato or waxy maize origin) as part of fluid resuscitation in comparison with other non-HES fluids after randomisation in the critical care setting". They put emphasis on "initial fluid resuscitation", since in the concluding remarks they state that "90-day mortality were significantly higher in severe sepsis patients receiving $6 \%$ tetrastarch $130 \mathrm{kDa}$ solutions as part of initial fluid resuscitation" [1]. Bearing that in mind, we wonder why the authors included reference 41 in which patients were randomized to either $6 \%$ HES 130/0.4, $250 \mathrm{ml}$ every $6 \mathrm{~h}$, or $20 \%$ albumin, $100 \mathrm{ml}$ every $12 \mathrm{~h} \mathrm{[2].}$
We would like to suggest more precise adherence to the inclusion criterion irrespective of a negligible effect on overall outcome. The administration of any fluid on a regular basis and in a fixed dose for more than 2 days cannot be considered as acute volume resuscitation.

However, this analysis [1] does not seem to be an exceptional case of arbitrary terminology of sepsis-related fluid resuscitation, since other analyses have focused on a comparable clinical scenario and outcome. The paper by Dolecek et al. in 2009 can be found in other systematic reviews as well $[3,4]$, including a recent paper on "fluid resuscitation" in this journal [5].

In summary, being more precise with the therapy under investigation in a meta-analysis and not solely focusing on the trial methodology, and assessing internal validity, may help avoid the potential for biased conclusions and thus help identify gaps in evidence. Such gaps still prevail in the acute phase of volume resuscitation in severe sepsis guided by valid parameters for the prediction of fluid responsiveness.

Conflicts of interest P.K. (LKP) is the coordinator of an investigator-initiated trial investigating acute volume resuscitation in severe sepsis and received funding from FreseniusKabi, Germany.

\section{References}

1. Patel A, Waheed U, Brett SJ (2013)

Randomised trials of $6 \%$ tetrastarch (hydroxyethyl starch $130 / 0.4$ or 0.42 ) for severe sepsis reporting mortality: systematic review and meta-analysis. Intensive Care Med 39:811-822
2. Dolecek M, Svoboda P, Kantorová I, Scheer P, Sas I, Bíbrová J, Radvanova J, Radvan M (2009) Therapeutic influence of $20 \%$ albumin versus $6 \%$

hydroxyethylstarch on extravascular lung water in septic patients: a randomized controlled trial. Hepatogastroenterology 56:1622-1628

3. Haase N, Perner A, Hennings LI, Siegemund M, Lauridsen B, Wetterslev M, Wetterslev J (2013) Hydroxyethyl starch 130/0.38-0.45 versus crystalloid or albumin in patients with sepsis: systematic review with meta-analysis and trial sequential analysis. BMJ 346:f839

4. Zarychanski R, Abou-Setta AM, Turgeon AF, Houston BL, McIntyre L, Marshall JC, Fergusson DA (2013) Association of hydroxyethyl starch administration with mortality and acute kidney injury in critically ill patients requiring volume resuscitation: a systematic review and meta-analysis. JAMA 309:678-688

5. Gattas DJ, Dan A, Myburgh J, Billot L, Lo S, Finfer S, CHEST Management Committee (2013) Fluid resuscitation with $6 \%$ hydroxyethyl starch (130/0.4 and $130 / 0.42$ ) in acutely ill patients: systematic review of effects on mortality and treatment with renal replacement therapy. Intensive Care Med 39:558-568

P. Kranke ( $)$ N. Roewer •

R. M. Muellenbach

Department of Anaesthesia and Critical Care, University Hospitals of Würzburg, Oberdürrbacher Str. 6, 97080 Würzburg, Germany

e-mail: kranke_p@klinik.uni-wuerzburg.de

Tel.: +49-931-201-30050

Fax: +49-931-201-30053

N. Roewer

e-mail: Anaesthesie-Direktion@klinik.uniwuerzburg.de

R. M. Muellenbach e-mail: muellenbac_r@klinik.uniwuerzburg.de 